\title{
O livro-reportagem no contexto do jornalismo e o correspondente internacional como jornalista-autor ${ }^{1}$
}

Beatriz Ostwald Luz Vilardo

Pontifícia Universidade Católica do Rio de Janeiro - PUC-Rio

Departamento de Comunicação Social - Bacharelado em Jornalismo

\section{RESUMO}

Da interseção entre o livro e o jornal, nasce o livro-reportagem: um híbrido entre o editorial e o jornalístico. Neste formato, o suporte livro passa a ter não só a conotação de meio de comunicação, mas também é apresentado como um espaço nobre para exercício do jornalismo. Correspondentes internacionais encontram nos livros-reportagem espaço para contar as histórias que não conseguem publicar na imprensa tradicional, mas que possuem valor em si. Neste artigo, trataremos do gênero livro-reportagem e de três obras de jornalistas-autores: "O inverno da guerra", de Joel Silveira; "Os últimos soldados da Guerra Fria", de Fernando Morais; e "Lua de mel em Kobane", de Patrícia Campos Mello.

\section{PALAVRAS-CHAVE:}

Jornalismo; Mercado editorial; Livro-reportagem; Correspondentes internacionais; Jornalismo literário.

\section{Introdução}

Livros. Geralmente associados a uma realidade fantasiosa, a um mundo inanimado que existe apenas na nossa imaginação e, somente, a partir da ação voluntária de ler. Jornais. O oposto. Ligados diretamente a fatos reais, de um mundo que existe e acontece independente da nossa vontade. Seja na educação, com os livros didáticos, na documentação histórica de um período, ou como forma de entretenimento, eles são fontes de conhecimento, cultura, desenvolvem o senso crítico, o vocabulário e a escrita.

Igualmente relevantes, os jornais servem como suporte de escrita e documentação dos acontecimentos, de maneira a moldar a nossa forma de pensar e enxergar o mundo. Independentemente de como entendemos o

\footnotetext{
1 Artigo derivado de monografia de graduação em Jornalismo, orientada pelo professor Felipe Gomberg e apresentada em dezembro de 2019.
} 
jornalismo: se como instrumento de construção da realidade ou como reflexo do real (AGUIAR, 2006). O fato é que, a partir dele, tomamos ciência de acontecimentos que, sem os veículos de comunicação, não teríamos contato.

Da interseção entre esses dois modelos de comunicação, nasce o livroreportagem: um híbrido entre o editorial e o jornalístico. Neste formato, o suporte livro passa a ter não só a conotação de meio de comunicação, mas também é apresentado como um "espaço nobre para exercício do jornalismo" (GOMBERG e VILARDO, 2018). Assim sendo, a lógica, antes vigente, é invertida: o jornal deixa de ser um espaço feito para a literautura (como os folhetins, por exemplo) e esta se transforma em suporte para o que antes the garantia prestígio. Não só os meios se transformaram e inverteram os papeis, também os profissionais seguiram o mesmo sentido. Se antes os literários exerciam a função dos jornalistas, hoje são os jornalistas que publicam livros. São os chamados jornalistas-autores.

Mesmo em meio a grandes nomes e prestígio, atualmente vive-se uma crise dos modelos de negócios em comunicação. Apesar do cenário desfavorecido, repórteres-autores ainda investem na produção do formato que descende do Novo Jornalismo, movimento com origem nos Estados Unidos nos anos 196070, como uma fase do Jornalismo Literário, e cujos principais nomes são Gay Talese e Tom Wolfe (MARTINEZ, 2017).

Correspondentes internacionais - especialmente os que trabalham em zonas de conflito - produzem grande volume de material tanto no quesito cobertura do confronto, como no da sociedade e da cultura locais. O jornalista depara-se com informações que não encontram espaço na imprensa tradicional, mas que possuem valor em si.

O profissional enxerga uma saída: o excedente do material que não pode ser explorado e explicado em detalhes nas mídias convencionais, ganha espaço no suporte livro, que não impõe limitações de tempo de produção e de espaço de publicação. "Guerras e conflitos nascem a partir de uma complexa trama histórica e envolvem fatores cuja análise em profundidade não é possível dentro do espaço midiático" (GOMBERG e WELIKSON, 2019, p.2). 
Neste artigo, abordaremos três obras - "O inverno da guerra", de Joel Silveira; "Os últimos soldados da Guerra Fria", de Fernando Morais; e "Lua de mel em Kobane", de Patrícia Campos Mello -, a fim de compreender como se deu o processo de apuração e produção do material e a influência do cenário de guerra nos autores. Esses livros-reportagem permitem uma análise histórica de três momentos de conflitos mundiais que tiveram ação entre os séculos XX e XXI. São eles: a Segunda Guerra Mundial, a Guerra Fria e a Guerra na Síria, respectivamente.

\section{O livro-reportagem no contexto do jornalismo}

Entre as tendências mais atuais das práticas comunicacionais, identificamos os deslocamentos de conteúdos por diferentes meios e suportes que, na era da convergência de mídias, a partir de uma multiplicação de narrativas transmidiáticas (FIGUEIREDO, 2017), transitam entre os diversos suportes: de documentários para seriados, da televisão tradicional para produtos on demand, de livros para os filmes, entre outros.

Aqui propomos pensar um desses deslocamentos que se associam ao jornalismo em mutação, apresentando-se no contexto dessa disrupção do jornalismo tradicional. Os textos antes publicados exclusivamente pelos jornais hoje passam a ser concebidos para a publicação em livros através de um formato híbrido entre o editorial e o jornalístico: o livro-reportagem. A forma livro-reportagem é hoje, por um lado, relevante gênero do mercado editorial, mas é, antes ainda, uma prática jornalística derivada do gênero reportagem a alterar a hierarquia no interior das redações.

Livro-reportagem (LIMA, 2009). Livro de repórter (ZAMIN, 2011). Romancereportagem (FERREIRA, 2004). Jornalismo literário (PENA, 2018). Jornalismo best-seller (CATALÃO, 2010). Essas são apenas algumas das formas de se referir às reportagens que extrapolam as páginas de jornais, de revistas e sites de veículos jornalísticos. Esse esforço literário em torno da reportagem pode nascer como resultado de uma grande reportagem ou uma série veiculada na imprensa ou ainda pode ter sido um projeto desde o início concebido para a publicação em livro. 
Na classificação de gêneros jornalísticos proposta por José Marques de Melo (MELO e ASSIS, 2010), o livro-reportagem assumiria a perspectiva do gênero diversional, uma vez que sua estrutura textual pode vir a contemplar a narrativa ficcional-literária, despertando vínculos com o leitor. Este, por sua vez, se aproxima da história narrada, através de recursos jornalísticos como a história de interesse humano ou a história colorida, mas distanciando-se da objetividade apregoada nas redações.

Esses projetos editoriais que propõem publicar reportagens em livro surgem no seio da redação, no âmbito do jornalismo, e atravessam essa fronteira invisível entre jornalismo e literatura. Edvaldo Pereira Lima publicou livro em que conceitua e classifica os livros-reportagem:

Entendendo a reportagem como a ampliação da notícia, a horizontalização do relato - no sentido da abordagem extensiva em termos de detalhes - e também sua verticalização - no sentido de aprofundamento da questão em foco, em busca de suas raízes, suas implicações, seus desdobramentos possíveis -, o livroreportagem é o veículo de comunicação impressa nãoperiódico que apresenta reportagens em grau de amplitude superior ao tratamento costumeiro nos meios de comunicação jornalística periódicos. Esse "grau de amplitude superior" pode ser entendido no sentido de maior ênfase de tratamento ao tema focalizado - quando comparado ao jornal, à revista ou aos meios eletrônicos - quer no aspecto extensivo, de horizontalização do relato, quer no aspecto intensivo, de aprofundamento, seja quanto à combinação desses dois fatores. (LIMA, 2009, p.28-29)

Outro fator que corrobora para a expansão de novos formatos de negócio na comunicação é o aumento da procura por conteúdos cada vez mais voltados para o micro em detrimento do macro. "O que este jornalismo não ligado às antigas empresas tem em comum no Brasil é estar voltado para um mercado de nicho" (MAURÍCIO, 2017, p.70-71).

Não apenas a estrutura das redações está se transformando, mas também o papel, a produção e até o modo de consumir as notícias. Com o advento da tecnologia, o aumento do uso de smartphones e de redes sociais, os algoritmos passam a "substituir" o trabalho dos editores, antes chamados gatekeepers, e passam a decidir "quais notícias serão exibidas para quais leitores, com base em comportamentos prévios, preferências individuais, geográficas e interesses 
comerciais", fato que demarca "comunidades isoladas umas das outras e que cada vez encerram-se mais em si mesma" (BARSOTTI e AGUIAR, 2018, p.123).

Muitos dos novos projetos editoriais do jornalismo na web lançam mão de textos ao estilo jornalismo literário. Pena (2006) lembra, por sua vez, que o jornalismo literário é um conceito amplo. Significa ultrapassar os limites dos acontecimentos cotidianos, proporcionar visões amplas da realidade, não devendo se confundir apenas com a ideia de "fugir das amarras da redação".

Ainda que não sejam sinônimos, jornalismo literário e livro-reportagem são conceitos que surgem a partir de uma produção jornalística que visa ampliar a compreensão da realidade. Abaixo reforça Lima (2009), no que tange aos objetivos do livro-reportagem:

[...] informar e orientar em profundidade sobre ocorrências sociais, episódios factuais, acontecimentos duradouros, situações, ideias e figuras humanas, de modo que ofereça ao leitor um quadro da contemporaneidade capaz de situá-lo diante de suas múltiplas realidades, de lhe mostrar o sentido, o significado do mundo contemporâneo. [...] Se cabe ao jornalismo informar e orientar, cabe ao seu subsistema, o livro-reportagem, informar e orientar com profundidade, transformando-se este último papel num instrumento complementador e extensor dessa função declarada, individualizadora do jornalismo (LIMA, 2009, p.39-49).

Para Catalão (2010), o jornalista, ao escrever um livro-reportagem, ocupa uma posição diferente de quando presente em uma redação. Isso porque, na nova condição, há a ausência da subordinação funcional e econômica.

Supera-se a posição de coadjuvante em uma relação dominada pela empresa, por seus donos, por agências de comunicação, anunciantes e agentes políticos, enfim, por uma série de atores cujos interesses condicionam diretamente o planejamento e a coleta, elaboração e transmissão de informações ao público. Assim, além da liberdade e da pessoalidade na definição da pauta, o caráter autoral do gênero permite ao repórter desvencilhar-se de constrangimentos enunciativos típicos de um campo marcado pela concentração de poder, pela normatização de procedimentos e de estilos, pelo cultivo da impessoalidade e por restrições temáticas, temporais e de espaço, dentre outras características. (CATALÃO, 2010, p.129). 
O suporte livro, além de solução para a manutenção de um jornalismo de qualidade, possibilita uma maneira de escapar das amarras das redações, e permite aos jornalistas "experimentar formas mais plurais e intersubjetivas de narrar a realidade" (MACIEL, 2017, p.9). Como muitos repórteres acumulam dupla função - de escritor e de jornalista diário nas redações -, muitos deles percebem, no livro, um lugar para reunir o que eles entendem como sendo o melhor de suas produções, encarando tal modalidade como portadora de "informação mais densa" (MACIEL, 2017, p.7).

\section{O correspondente internacional como jornalista-autor}

O fazer jornalístico é de tal modo reconfigurado nos livros-reportagem, que, a partir dos anos 1980, os livros cujos autores eram jornalistas foram deixando de ser utilizado para a publicação de crônicas ou reportagens que já tinham obtido o reconhecimento público nos jornais diários para tornarem-se projetos profissionais de jornalistas-autores (MACIEL, 2017).

Pesquisadores da história da imprensa no Brasil indicam os anos 1950 como um momento marcado pela busca da independência do jornalismo em relação à literatura. Neste período, buscou-se um afastamento da escrita pessoalizada, e o lead surgiu como um caminho para a objetividade.

Editoras como Companhia das Letras, Recorde, Geração Editorial e Planeta, dentre outras menores, perceberam o valor e o solo fértil que se tornou o segmento dos livros de não-ficção escritos por jornalistas, e passaram a incentivar suas publicações. Profissionais veteranos nas redações se desafiaram em uma nova empreitada: dedicar-se por anos na produção de obras exclusivas em livros. O resultado foi, em sua maior parte, sucesso com o público (MACIEL, 2017).

Correspondentes internacionais têm, em grande parte, cenário mais propício para explorar o formato, uma vez que seu tempo nos veículos tradicionais é reduzido se comparado ao volume de material que eles produzem. Tal fator pode ser multiplicado quando se trata da cobertura de uma zona de conflito, uma vez que as possibilidades de "horizontalização" e "verticalização" do tema, como conceitua Lima, são esgarçadas. O jornalista, então, depara-se com 
informações que não encontram lugar na imprensa tradicional, mas que possuem valor em si.

O trabalho exercido pelo correspondente de guerra é gratificante e rende prestígio para o jornalista que o desempenha. O profissional, ao aceitar realizar cobertura em zonas de confrontos, leva em consideração a experiência única e o reconhecimento advindos do ofício.

Para Gomberg e Welikson, "ter a experiência de viver e trabalhar como jornalista em ambiente de conflito é aprender sobre o local que é palco dos importantes acontecimentos noticiosos e que marcam o desenrolar da História, tornando-se um relevante desafio tanto profissional quanto pessoalmente" (2019, p. 11).

Qualquer que seja a situação em que o jornalista se enquadre, haverá uma transformação no modo de pensar dele, uma vez que o profissional irá confrontar com realidades econômica, cultural e social diferentes das próprias. Tal fato não excluirá as bases que tinha, mas somará para a forma como ele irá relatar os acontecimentos. "Na cobertura midiática de guerras, existe uma linha bastante tênue entre o relato frio e distanciado dos acontecimentos e o envolvimento com a causa a ser reportada" (GOMBERG e WELIKSON, 2019, p. 18).

Esses fatores culminam numa estrutura narrativa de livros-reportagem com maior peso na descrição dos ambientes e na reconstituição dos personagens e das situações. Isso graças ao olhar do jornalista-autor sobre a realidade, ao qual Maciel chama de "cronistas, observadores de mazelas sociais, 'flanadores' dos recônditos das metrópoles e do campo e investigadores das mudanças comportamentais, sociais e econômicas" (MACIEL, 2019, p.1).

O livro-reportagem permite maior e minuciosa descrição dos personagens e dos fatos e, no caso de correspondentes internacionais, a combinação entre as realidades e culturas dos dois países (o de origem e o que se encontra) influencia e enriquece os relatos.

O livro-reportagem é um produto cultural contemporâneo bastante peculiar. De um lado, amplia o trabalho da imprensa cotidiana, como que concedendo uma espécie de sobrevida aos tratados pelos jornais, pelas revistas, emissoras de rádio e televisão. De outro, 
penetra em campos desprezados ou superficialmente tratados pelos veículos jornalísticos periódicos, recuperando para o leitor a gratificante viagem pelo conhecimento da contemporaneidade (LIMA, 2009, p.7).

Os livros-reportagem escritos por correspondentes internacionais em zonas de conflito, portanto, funcionam como um híbrido entre o jornalismo, a literatura e a história. Entretanto, as dificuldades dos correspondentes de guerra que escrevem livro-reportagem não se situam apenas no quesito zonas perigosas e risco de vida. Ela perpassa os desafios de um mercado (editorial) que, atualmente, encontra-se em momentos de instabilidade.

\section{Análise dos livros-reportagem}

\subsection{O inverno da guerra}

Trata-se de um compilado de reportagens do jornalista e escritor Joel Silveira durante o período em que foi correspondente de guerra. Aos 26 anos, ele foi enviado à Itália para cobrir a Segunda Guerra Mundial ao lado da Força Expedicionária Brasileira (FEB), pelos Diários Associados. Assis Chateaubriand, dono da rede de mídias, ao escalar Joel para a função, alertou: "Você vá, mas não me morra!".

Joel Silveira, apelidado por Chateaubriand de "Víbora", é considerado o repórter que mudou o jornalismo nacional, por ter introduzido um estilo mais literário nos textos - mesmo duas décadas antes de Gay Talese, um dos pais do new journalism.

Originalmente, as reportagens que compõem $O$ inverno da guerra foram publicadas no livro Histórias de Pracinha. O próprio autor, na época em que voltou da Guerra, juntou textos que havia escrito durante o período em que acompanhou o front da FEB, como uma espécie de diário de bordo. Histórias de Pracinha, lançado em 1946 pela Editora Leitura, está esgotado há mais de 30 anos. Relançado em 2005, o livro-reportagem é parte da coleção Jornalismo de Guerra, organizada pela editora Objetiva para comemorar os 60 anos do fim da Segunda Grande Guerra. Na edição da Objetiva, foi acrescentada uma introdução exclusiva escrita pelo jornalista. "Nela, são resgatados um pouco do 
cotidiano do correspondente na Itália e as condições em que teve que realizar seu trabalho" (MIRANDA, 2007, p.81).

O livro traz relatos desde antes do desembarque na Europa, já no navio, em uma travessia junto a seis mil soldados. Os relatos narram a chegada a uma "Itália semi-destruída", a relação de Joel com outros correspondentes e o perigoso trabalho de apuração e convívio com pracinhas e oficiais durante o confronto.

O jornalista-autor narra as cenas que vê, descreve os cheiros, as dificuldades de se estar em uma guerra, desde a incerteza sobre se conseguirá voltar para o lugar de dormir (tanto pela possibilidade da morte como pela impossibilidade física ou de segurança) e, com isso, a necessidade de levar aparatos para o frio e para o envio de matérias aos Diários Associados, até as sensações e sentimentos compartilhados por todos que experienciam uma situação hostil como uma guerra. "Sofremos bastante lá nos Apeninos. Medo, frio - muito frio -, desconforto e aquele constante odor de sangue velho e óleo diesel, que é o cheiro da guerra" (SILVEIRA, 2005, p.3).

A escrita de Joel "constrói visualmente cenas e acontecimentos da guerra. Ao lermos o livro, temos a impressão de que assistimos a um filme que é projetado em nossa tela interior" (MIRANDA, 2007, p.83).

E lá íamos subindo, subindo a 30 quilômetros por hora, com as correntes que envolviam os pneus estilhaçando o gelo, num jipe sem capota nem para-brisa. No front, para-brisa, como sabem - ou não sabem? -, é proibido, já que o simples clarão de qualquer luz nele refletida pode indicar ao inimigo a sua sempre excitada pontaria. $\mathrm{E}$, pelos mesmos motivos, nem pensar em acender os faróis, por mais cerrada que estivesse a neblina, e quase sempre estava. [...] A tática do motorista Adão não era bem uma tática, mas algo assim como quem joga a última ficha na roleta: antes da ponte, ele dava uma parada, mandava que nos abaixássemos e nos encolhêssemos o máximo possível. E após uma rápida concentração, as mãos apertando tensas o volante, o bravo cabo-motorista soltava seu grito de guerra: - Deus é grande! $E$, numa só arrancada, o seu brioso jipe voava pela ponte, aos solavancos, sem dar importância a uma ou outra granada de morteiro que explodia perto ou afundava nas tranquilas e murmurantes águas do rio. (SILVEIRA, 2005, p.35) 
O trecho destacado comprova a afirmativa anterior. Ao descrever a cena, Silveira detalha com uma precisão que nos permite ser capazes de não só imaginá-la, mas suscita um sentimento de tensão no leitor. O mesmo sentimento vivenciado pelo jornalista.

Na obra de Joel Silveira, percebe-se, de forma clara, a influência que o ambiente ao redor exerce sobre o jornalista. "Por isso é que costumo dizer que cheguei à Itália com 26 anos e voltei com 40, embora lá só ficasse pouco mais de oito meses. [...] A guerra, repito, é nojenta. E o que ela nos tira (quando não nos tira a vida) nunca mais nos devolve" (SILVEIRA, 2005, p.20).

A experiência como correspondente de guerra trouxe não apenas notoriedade ao já reconhecido jornalista, mas também ocasionou um aspecto negativo, e deixou uma lacuna na fase da vida a que o próprio Joel chama de mocidade.

\subsection{Os últimos soldados da Guerra Fria}

Em setembro de 1998, dez agentes cubanos foram detidos em Miami pelo FBI, Departamento Federal de Investigação dos Estados Unidos. O grupo foi acusado de ser integrante da "Rede Vespa", maior organização de espiões cubanos nos Estados Unidos, que tinha por objetivo deter ataques terroristas contra Cuba. (PRESSE, 2015). Na época, o jornalista Fernando Morais soube da notícia através de uma rádio, e percebeu que a história rendia mais do que uma simples reportagem. Morais foi à Cuba pesquisar mais sobre o caso, mas não obteve sucesso, pois as informações eram mantidas em sigilo.

Os cubanos foram condenados à prisão três anos depois, em 2001, mesmo ano em que Cuba assumiu que eles eram, de fato, agentes de inteligência. Mas foi somente em 2008, 10 anos depois das detenções, que Morais obteve acesso aos documentos e aos agentes cubanos.

Ao todo foram cerca de 20 viagens entre Havana, Miami e Nova York. Nos territórios americanos, Morais encontrou mais obstáculos, já que os agentes do FBI são proibidos de dar declarações públicas. Entretanto, ele conseguiu entrevistas em off e o apoio da lei americana FOIA (Freedom of Information Act), que regula a liberação de documentos secretos. Assim, teve acesso, nos arquivos da Justiça Federal da Flórida, a cerca de 30 mil documentos enviados 
pela Rede Vespa à Cuba e que haviam sido apreendidos pelo FBI nas casas dos agentes cubanos em Miami.

As pesquisas, entrevistas e viagens resultaram no livro Os últimos soldados da Guerra Fria: A história dos agentes secretos infiltrados por Cuba em organizações de extrema direita dos Estados Unidos, publicado 10 anos depois da prisão dos cubanos, em 2011, pela Companhia das Letras.

O livro dividido em 15 capítulos mais epílogo narra a aventura dos espiões cubanos em território americano. Ele revela detalhes de uma rede terrorista com sede na Flórida e ramificações na América Central, que tem o apoio tácito nos Estados Unidos de membros do Poder Legislativo e com certa complacência do Executivo e do Judiciário.

Para contar a história dos "Cinco de Cuba", como são
chamados Fernando González, René González, Gerardo
Hernández, Ramón Salazar e Antonio Guerrero, que
cumprem penas que variam de 18 anos de cadeia a
prisão perpétua, Morais optou pela narrativa linear,
mostrando-os inicialmente como desertores que
abandonam as forças armadas, a pátria e a família,
cansados dos desmandos da "ditadura castrista"
(OTÁVIO, 2011).

Fotos dos agentes, dos locais e objetos que foram alvo dos cubanos, de cenários e armas por eles usados, de esquemas e de documentos ajudam a contar e a desenhar a complexa trama dos agentes secretos cubanos infiltrados em organizações de extrema direita nos Estados Unidos. No início de cada novo capítulo, há uma espécie de resumo, em uma ou duas frases curtas, que sintetiza o que será tratado na próxima parte do livro.

De forma diferente do jornalista anterior, Fernando Morais não presenciou o confronto que relata, portanto não sofreu diretamente a tensão de um conflito. O livro-reportagem foi construído à base de entrevistas e depoimentos de pessoas envolvidas direta e indiretamente, além de análises de documentos, livros, jornais, revistas, filmes e documentários.

Apesar de o jornalista-autor não estar presente nas situações que descreve, o livro-reportagem não carece de detalhes. "As chamas expelidas pelas duas turbinas do caça super-sônico deixavam no ar uma cauda de fogo, como se um cometa tivesse cortado o azul do céu em plena luz do dia. Pesando dez 
toneladas, o MiG-29 cinza-escuro estava armado com quatro mísseis ar-ar, seis mísseis ar-terra, um estoque de bombas guiadas a laser e um canhão de trinta milímetros com capacidade para 150 disparos" (MORAIS, 2011, p.189).

Com tantos documentos impressos no livro, diálogos transcritos, inclusive o da comunicação entre a torre de controle de Havana e os dois aviões relacionados aos bombardeios que desencadearam a morte de quatro pilotos americanos, Os últimos soldados da Guerra Fria funciona como documentação de um conflito, em especial a infiltração de agentes secretos cubanos, que durante anos foi escondido pelo governo cubano, e cujas informações importantes também estavam sob sigilo americano.

A obra de Morais demonstra que a produção de um livro-reportagem sobre uma zona de conflito não necessariamente precisa ser realizada no momento em que o confronto ocorre, mas sim que necessita de um bom e longo trabalho de apuração e entrevistas.

Aluno brilhante em todas as escolas por onde passou, em 1974 foi admitido na União dos Jovens Comunistas e cinco anos depois, ao terminar o pré-universitário, conquistou uma bolsa para estudar engenharia aeroportuária na Universidade de Kiev, na Ucrânia. Ao retornar para Cuba, trabalhou no setor de obras da Cubana de Aviación até ser escolhido para chefiar a ampliação do aeroporto Antonio Maceo, na cidade de Santiago [...]. Em 1988, ao voltar a Havana sozinho e divorciado, foi recrutado pelo Ministério do Interior para trabalhar como agente de inteligência (MORAIS, 2011, p.130).

O trecho acima destacado detalha acontecimentos da vida de Antonio Tony Guerrero, um dos agentes cubanos da Rede Vespa infiltrado em organizações anticastristas nos Estados Unidos. O recorte evidencia o que Lima (2009) chama de "horizontalização" e "verticalização", ao aprofundar as informações sobre o ocorrido que não apareceriam na imprensa tradicional, mas que traz detalhes relevantes para o entendimento do ocorrido. Neste caso específico, o autor buscou informações que dão base para a construção de um personagem, ampliando "horizontalmente" a gama de dados sobre o caso e o entendimento para a construção de quem era a pessoa.

\subsection{Lua de mel em Kobane}

"O motorista pediu ajuda para colocar os cadáveres no carro. Eram sete sacos azuis. 'Rápido, rápido', dizia. 'Não quero ficar aqui muito tempo.' Ao longe, era possível escutar as explosões de morteiros" (MELLO, 2017, p.9). 
Assim poderia começar um livro de romance policial qualquer, em que, no desenrolar da história, o detetive iria atrás de pistas que entregassem o autor de um crime quase perfeito. Assim começa o livro-reportagem Lua de mel em Kobane. Um fato real acontecido num passado bem próximo e ainda em andamento.

Escrito pela jornalista Patrícia Campos Mello e publicado em 2017 pela Editora Companhia das Letras, Lua de mel em Kobane narra a história de um jornalista e de uma estudante de Direito que se conheceram pela Internet. Ambos compartilhavam não só a naturalidade (síria), mas também o fato de estarem exilados do seu país de origem.

O livro-reportagem tem como pano de fundo a Guerra na Síria, e narra os desafios e dilemas do jovem casal que arriscou a vida para viver juntos em Kobane, cidade que fica na fronteira com a Turquia e sitiada pelo Estado Islâmico. No movimento contrário ao de milhares de pessoas que, entre 2014 e 2015, saíram da Síria para fugir da guerra com o Estado Islâmico, o casal quis escrever a própria história sendo, ao mesmo tempo, testemunhas da História.

Barzan Iso é um jornalista curdo-sírio que havia escrito uma série de reportagens sobre a relação do Estado Islâmico e Kobane, mas que havia sido afastado de seu país e se refugiado na Turquia, por militar a favor da independência curda. Raushan Khalil, a mulher, estudava Direito na Universidade de Alepo quando se viu obrigada a interromper os estudos devido à violência provocada pelos extremistas religiosos. Ela foi para a Rússia, onde alguns membros da família moravam, para garantir maior segurança. Ambos são curdos, povo sem Estado que luta por independência e autonomia política.

Exilados, Barzan e Raushan se conheceram em uma rede social e engataram um caso de amor em meio à disputa pelos territórios curdos. Já casados, foram agentes ativos na resistência de Kobane. O livro-reportagem conta a história do casal e tem como pano de fundo o contexto histórico e geopolítico do local.

Na narrativa, Patrícia:

aproxima o leitor da realidade de um dos países mais complexos do Oriente Médio, para muito além do que é 


\begin{abstract}
transmitido pela mídia brasileira, com sua limitada cobertura do noticiário internacional. Os fatos hostis da sangrenta Guerra da Síria ganham traços humanos à medida que conhecemos a história de Raushan e Barzan [...]. (MAGNOLI, 2018)
\end{abstract}

Tais traços reforçam a perspectiva do gênero diversional, de acordo com Melo (MELO e ASSIS, 2010), uma vez que desperta vínculos com o leitor, e exemplifica, também, o que Catalão chama de "restrições temáticas, temporais e de espaço" (CATALÃO, 2010, p.129). O trecho retrata que o livro-reportagem não só amplia o trabalho da imprensa cotidiana, como a adentra em campos desprezados ou superficialmente tratados pelos veículos jornalísticos periódicos (LIMA, 2009).

Além da disputa territorial entre curdos, sírios, turcos e extremistas, Patrícia também relata a importância da participação feminina no conflito e documenta que as mulheres foram responsáveis pela tomada de Kobane. A guerra civil síria, portanto, transformou-se em uma história que começou na Primavera Árabe e desembocou na resistência feminina.

No livro-reportagem, a jornalista-autora intercala momentos narrados em primeira e em terceira pessoa. Quando explica a Guerra na Síria, a Primavera Árabe, a eclosão do Estado Islâmico e a própria história do casal, Patrícia escreve na terceira pessoa. Entretanto, para situar o leitor sobre o motivo que a levou à Kobane e quando conta momentos vividos por ela junto a Barzan e Raushan, a autora se permite utilizar a primeira pessoa - no singular e no plural respectivamente.

\title{
5. Considerações finais
}

A partir da leitura da bibliografia sobre o assunto e ao analisar os três objetos selecionados, pude observar que os livros-reportagem possuem uma forma menos engessada e mais livre de escrever. O estilo utiliza recursos literários, com reportagens mais detalhadas e descritivas, sem a necessidade do formato pirâmide invertida, em que logo no início o leitor recebe a informação mais importante e posteriormente há níveis hierárquicos de relevância dos dados. 
No livro-reportagem, há a possibilidade de influência pessoal do jornalista, que pode expor sua opinião embasada em suas vivências, embora isso não seja uma regra. Diferentemente dos estilos presentes nas redações tradicionais, que obrigam o repórter a escrever da maneira mais imparcial possível.

A escrita concisa também é um fator diferencial relevante. No suporte livro, os profissionais podem escrever sem a preocupação da limitação espacial e temporal, o que o permite elaborar e detalhar melhor a reportagem, trazendo mais informações para o leitor.

Além disso, o suporte livro é uma das soluções que vêm sendo utilizadas para a crise financeira que assola as redações tradicionais. Tanto no quesito explorar uma mesma notícia de diferentes formas, como na manutenção de um jornalismo de qualidade, uma vez que tal preocupação se faz presente pelo fato de os profissionais, nas redações, estarem acumulando diferentes funções.

O formato, que não surgiu com a crise na imprensa, mas se aproveitou dela como alternativa para crescer, encontra apoio do público, que demonstra interesse por este gênero editorial. O campo do livro-reportagem é amplo e pode ser explorado de diferentes formas, como dito por Lima.

As três obras exemplificam o que Maciel (2017) descreveu como um "potencial de perenidade", o que os permite funcionar, também, como documentação histórica, como forma de registrar os horrores que o ser humano é capaz de cometer e, de certa forma, evitar que essa barbárie seja esquecida e mesmo repetida.

\section{Referências bibliográficas}

AGUIAR, Leonel Azevedo de. Critérios de noticiabilidade no jornalismo investigativo: um estudo preliminar. In: XXIX Congresso Brasileiro de Ciências da Comunicação. Intercom, UnB, 2006.

BARSOTTI, Adriana e AGUIAR, Leonel. Mudanças nos modos de leitura das notícias e perda de importância da home page. Alceu, v.18, n.36, p.122-141, jan-jun./2018.

CATALÃO JR., Antônio Heriberto. Jornalismo Best-seller: o livroreportagem no Brasil contemporâneo. Tese doutorado - Universidade 
Estadual Paulista, Faculdade de Ciências e Letras, Campus de Araraquara, 2010.

FIGUEIREDO, V. Follain de. Narrativa e temporalidade na cultura midiática.

Tríade: Comunicação, Cultura e Mídia, v.5, n.9, p.128-139, jun./2017. GOMBERG, Felipe. A aura do livro na era de sua reprodutibilidade técnica. Dissertação de mestrado. Departamento de Comunicação. PUC-Rio, 2006.

GOMBERG, Felipe; VILARDO, Beatriz. Na fronteira entre jornalismo e literatura: um levantamento das pesquisas mais atuais em livro-reportagem nos congressos da SBPJor. In: VIII Encontro Nacional de Jovens

Pesquisadores em Jornalismo, JPJOR, 2018.

GOMBERG, Felipe; WELIKSON, Camila. Os correspondentes internacionais em zonas de conflito: ética, produção de notícia e teorias do jornalismo no ensino da profissão. In: $\mathbf{1 8}^{\circ}$ Encontro Nacional de Professores de Jornalismo, ENPJ, 2019.

LIMA, Edvaldo Pereira. Páginas ampliadas: livro-reportagem como extensão do jornalismo. 4.ed. São Paulo: Manole, 2009.

MACIEL, Alexandre Zarate. "Pressão da editora é mínima. A pessoal é enorme": jornalistas e a produção do livro-reportagem. In: $1^{\circ}$ Encontro da Associação Nacional de Pesquisadores em Jornalismo SBPJor, 2017. MACIEL, Alexandre Zarate. "Narradores do Contemporâneo: Jornalistas Escritores e o Livro-reportagem no Brasil". Intercom, maio/jun. 2019. MARTINEZ, Monica. Jornalismo Literário: revisão conceitual, história e novas perspectivas. Intercom, v. 40, n. 3, p.21-36, set./dez. 2017. MAURÍCIO, Patrícia. A desintegração do modelo de negócios do jornalismo e tentativas para financiar reportagens de qualidade na internet. Alceu, v.18, n.35, p.62-78, jul-dez./2017.

MELLO, Patricia Campos. Lua de mel em Kobane. São Paulo: Companhia das Letras, 2017.

MELO, José Marques de; ASSIS, Francisco de. (Orgs.). Gêneros jornalísticos no Brasil. São Bernardo do Campo: Universidade Metodista de São Paulo, 2010.

MORAIS, Fernando. Os últimos soldados da Guerra Fria. São Paulo: Companhia das Letras, 2011. PENA, Felipe. O jornalismo Literário como gênero e conceito. In: XXIX Congresso Brasileiro de Ciências da Comunicação. UnB, 2006, Intercom. PENA, Felipe. Jornalismo literário. São Paulo: Contexto. 2018. 
SILVEIRA, Joel. O inverno da guerra. Rio de Janeiro: Objetiva, 2005.

ZAMIN, Angela. Livros de repórter, saberes de entremeio: relatos jornalísticos sobre a cobertura de conflitos. Estudos em Jornalismo e Mídia, v. 8, p.389-405, 2011. 